\title{
Analysis of Quality Indicators through Fast Fashion and Classic Brands of Jeans for the Apparel Consumer
}

\author{
Katelyn Haas $^{1^{*}}$ and Dr. Usha Chowhdary ${ }^{2}$ \\ ${ }^{1}$ Graduate Student, Central Michigan University, USA \\ ${ }^{2}$ Professor, Central Michigan University, USA
}

*Corresponding author: Katelyn Haas, Graduate Student, Department of Fashion, Interior Design, and Merchandising, Central Michigan University, USA.

Received Date: April 01, 2021

Published Date: April 27, 2021

\begin{abstract}
The fast fashion industry is growing rapidly, as is its consumer market. Consumers frequently purchase from these brands knowing the quality of garments may be diminished. This study aimed to provide insight to the consumer to recognize the quality in correlation to the price of a garment, through examining the structural and performance attributes. Multiple hypotheses were developed based on existing research. While the two denims differed in structural and performance attributes, these did not seem to impact the seam efficiency of denims, as their results were similar. This research can provide insight not only to manufacturers and retailers, but also the consumer in smarter shopping and recognizing the quality that is paid for.
\end{abstract}

Keywords: Quality indicator; Denim; Jeans; Consumer; Price; Seam strength; Seam efficiency

Abbreviations: LMIC: Low-to-middle income countries; SPI: Stitches per inch; ASTM: American Society for Testing and Materials ; AATCC: American Association of Textile Chemists and Colorists

\section{Introduction}

In an era of social media and everyday people feeling more in the public eye, the appeal of having the newest or trendiest clothing has deeply impacted society's sense of consumerism. There is a constant change in trends which, in turn, has helped fuel the fast fashion industry. This demand requires a continuous production of garments at the lowest price possible [1]. The fast fashion industry is producing clothing faster than ever, practically guaranteeing lower quality garments. These fast fashion styles typically mirror luxury fashion trends, making them even more desirable. Consumers are able to get this look at a sliver of the cost of authentic luxury pieces, but these garments are not made to last. The fast fashion industry encourages disposability [2]. However, while consumers grasp the concept that fast fashion is harmful to the environment, they tend to turn a blind eye when making fast fashion purchases and think to make up for sustainability in other areas of life [3]. In regard to garment quality, seam efficiency is an important indicator that is dependent on strength, elasticity, stability, and appearance [4].

While it is common to assume fast fashion produces low quality pieces, there is little to no academic research on the actual quality of fast fashion garments. When it comes to staple items in wardrobes, like classic denim jeans, is spending more worth the investment? This study has examined the impact that structural and performance attributes have on seam strength and efficiency in fast fashion jeans versus classic jeans at the next highest price point. This will provide the industry and consumers with critical information. This research can give retailers and manufacturers guidance on the types of materials and seams they could use to produce a 
better denim garment. It may also provide insight to consumers for smarter shopping and an overall awareness of what indicates quality. Therefore, the main purpose of the reported study was to compare the impact of fabric count, fabric weight, and stitch density on colorfastness to crocking, dimensional stability, pilling resistance, seam strength and seam efficiency of different priced denims.

The term fast fashion is quickly on its way to being interchangeable with "landfill fashion," [5]. A high volume of manufacturing encourages consumers to keep buying new items and view their past purchases as disposable. The average American throws away around eighty pounds of clothing annually. Each year, about one billion pounds of clothes are exported from the United States to low-to-middle income countries (LMICs) [6]. Consumers may be surprised to learn that fast fashion retailers actually provide an average benchmark for the number of washes garments can withstand. After about ten washes, garments are expected to not retain their original values due to poor quality materials and manufacturing [7].

This mindset of disposability is also supported by fast fashion's quick lead time. Lead time refers to the time a brand can design, produce, and deliver new garments. $H \& M$ has a lead time of 8 weeks, forever 21 at 6 weeks, and Zara is at a rapid 2 weeks [8]. With such a high turnover and new products released so frequently, consumers can get bored of their wardrobes quickly. While the ethical and environmental impacts of fast fashion are clear to the consumer, it has not resulted in a decline of interest. Fast fashion provides accessibility of stylish pieces, and the possibilities of extending one's sense of self. This has developed avid consumers that browse fast fashion stores more than once a month to check out and purchase new pieces [9]. Retailers have their process down to a science which allows for better efficiency in meeting consumer demand. This high demand being on such a tight schedule allows fast fashion companies to seek out higher-cost local labor and expedited shipping because future financial returns far exceed this current cost [10].

Previous research includes studies relating the seam efficiency, elongation, breaking strength, and more, over different fabrics and fabric combinations. Chowdhary studied the elongation, breaking strength, and break time for $100 \%$ medium weight knitted wool, alongside interfacings and linings [11]. Research found that the addition of interfacing did not always result in an increased strength or reduction of elongation. This study also confirmed that interfacing did not enhance strength, but lining did. Further research among this could be conducted with various fiber contents of fashion fabrics. Extending this research could provide advantageous insight to manufacturers, retailers, and consumers alike [12].

Chowdhary and Poynor also studied the seam efficiency, seam strength, and seam elongation for premium muslin with three varying stitch densities [13]. The study tested the relationship between seam strength and stitch density of a superimposed seam, elonga- tion and stitch density of a superimposed seam, fabric strength and seam strength, fabric elongation and seam elongation, and seam efficiency and stitch density. Results concluded that there were significant differences for seam strength between the three stitch densities in the warp and filling directions. Stitch density influences strength and elongation, therefore testing for other variables, such as thread type, yarn size, and yarn type, would provide those in the field with more information to make educated decisions [14].

Chowdhary and Wentela examined the impact of support fabrics on strength elongation, and time taken to complete tests on a variation of woven fabrics and fiber contents [15]. The study concluded that support fabrics impact elongation, strength, and time take to break the fabric differentially for various fiber contents. Research also showed that an increase in strength did not always result in a decreased elongation for sewn fabrics. Also, the addition of interfacing didn't always increase the strength of the fashion fabric, which was supported by previous research. This study also concluded that polyester was stronger than acetate when used as a lining. Recommendations included further research on the dynamics of textiles when combined with other woven, nonwoven, or knitted materials to provide durability and comfort for the consumer. This approach could be looked at for professional attire [16].

Shweta and Poulomi examined the effects of yarn size in tex and stitch density on the seam performance in denim fabric [17]. Medium-heavy and heavy weight denim fabrics were selected and superimposed plain seams were used with a 301-stitch type. The study examined the possible differences with using thread sizes of sixty, ninety, and one-hundred-and-fifty tex, with stitch densities of ten and thirteen. All combinations showed seam strength increased as both yarn size and stitch density increased, except for the medium-heavy denim used with a ninety tex yarn and thirteen stitches per inch (SPI). This was found to be true for seam elongation as well, where the medium-heavy denim with a ninety tex yarn size resulted in $15.6 \mathrm{~mm}$ for both ten and thirteen SPI. Overall, the study discovered that for the heavy weight denim, the independent variables had no significant effect on the seam quality but did for the medium-heavy weight denim. Statistically, there was a significance between stitch density, sewing thread count, and fabric weight on the strength, elongation, and efficiency of the seam [18].

Malek, Jaouachi, Khedher, Ben Said, and Cheikhrouhou studied the effect of the seam threads linear density, stitch density, and various fabric properties on the seam efficiency of eighteen denims of varying fiber contents [19]. In the $100 \%$ cotton denims, seam efficiency increased when stitch density and tex were higher. However, the increase of fabric mass had random effects on seam efficiency where results were either positive correlations or inversely proportional [20].

Farashahi studied colorfastness to crocking in various priced denims. Both dry and wet tests were conducted [21]. For dry testing, the initial sample for the most expensive jeans averaged a rat- 
ing of 4.14, while the two more affordable jeans averaged 4.22 and 4.78. After the fifth wash, the most expensive jeans averaged a rating of 4.53 and the two more affordable jeans averaged 4.64 and 4.75. Here, the cheapest pair of jeans had the best ratings and the level of staining remained unchanged after home laundering [22]. As for the wet tests, the most expensive jeans initial average was 1.94 while the other two were 2.11 and 2.83. After the fifth wash the most expensive pair averaged a rating of 2.31 and the other two averaged ratings of 3.03 and 3.58. Again, the cheapest pair of jeans showed the least amount of staining.

Farashahi's study also looked into the dimensional stability of the three jeans. The highest priced jeans had an average dimensional change of $1.09 \%$ in length and $1.03 \%$ in width. Shrinkage for the second lowest priced jeans was $1.27 \%$ in length and $1.76 \%$ in width. Finally, the cheapest jeans averaged a $1.57 \%$ change in length and a $.94 \%$ change in width. These results complied with the measured fabric counts [23].

Card, Moore, and Ankeny studied the impact of laundering on the abrasion and pilling resistance on garment washed jeans [24]. The study revealed that the pre-washed garments experienced more pilling compared to the enzyme treated and stone washed garments. The pre-washed denim had a mean rating of 4.21 , the enzyme washed average was 4.47 , and the stone washed average was 4.61. The researchers found that this was due to the surface fibers of the pre-washed jeans had not been dissolved through enzyme washing or abraded away through stone washing [25].

Research in testing the seam strength, seam efficiency, and elongation and breaking strength (grab test) will be conducted in relationship to the denims' structural attributes. This research will benefit the industry and consumer, as little to no solidified research has been conducted in academia regarding fast fashion textiles. In turn, this study should give insight to consumers on what is worth their money and will provide the industry a better understanding of the implications of cheaply made materials. The following hypotheses were formulated based on the literature review.

1. The breaking strength between two different priced denim jeans will differ.

2. The elongation between two different priced denim jeans will differ.

3. The stitch density between two different priced denim jeans will differ.

4. The color fastness to crocking between two different priced denim jeans will differ.

5. The dimensional stability between two different priced denim jeans will differ.

6. The pilling resistance between two different priced denim jeans will differ.
7. The seam efficiency between two different priced denim jeans will differ.

8. The fabric count will impact seam strength.

9. Fabric weight will impact seam strength.

\section{Materials and Methods}

This study examined the structural and performance attributes of two brands of jeans. The two pairs are popular/best sellers at two different retailers. Denim A is a $100 \%$ cotton denim, high rise, straight leg jean from a popular fast fashion retailer that cost $\$ 39.95$. Denim B is a $100 \%$ cotton denim, high rise, straight leg jean but purchased from a contemporary retailer that cost $\$ 79.95$. Both were purchased in a size 14. Multiple pairs of both jeans were purchased and cut into specimens for testing.

ASTM standards were used to measure five structural attributes and five performance attributes. Some tests used modified specimen sizes as to work with finished garments used for this study and are distinguished in Table 1 below. All specimens were conditioned under ASTM standard D1776. The four structural attributes were yarn size, weave type, fabric count, and fabric weight; the five performance attributes were dimensional stability, seam strength and efficiency, pilling resistance, color fastness to crocking, and fabric strength and elongation. Table 1 shows all attributes tested for and the ASTM or AATCC standard related.

Yarn structure is important in determining and sustaining the quality of a textile and garment [26]. Yarn structure was analyzed in this research, but fiber content was not, as the retailers provided information stating that both jeans were made of $100 \%$ cotton.

Yarn size is the linear density measured as mass per unit length. This study used the TEX method in which a unit equals weight in grams of one kilometer [27]. The TEX system consists of the measurement of ten specimens each equivalent of one-meter yards in both warp and weft directions. Specimens were then conditioned and weighed in grams and each reading was multiplied by 1000 to convert into TEX.

Fabric count refers to the number of warp and weft yarns per unit length of fabric under zero tension, wrinkles, and folds [28] Five specimens of 1"x1" squares were measured. A pick needle and linen tester was then used to count the warp and weft yarns. Denims were then classified as low, medium, or high, as per Collier and Epps.

For fabric weight, five specimens at 5 " $\mathrm{x} 5$ " were weighed in grams on a scale. Recordings were taken and then converted to ounces per square yard and grams per square meter. Mean and standard deviation were calculated, and the denims were classified by weight.

Dimensional stability determines changes in fabrics after being exposed to laundering [29]. The standard specimen size is 15 "x15" 
for woven fabrics. Due to limitation of using sewn garments rather than flat yardage, dimensions were reduced to half. Five specimens were modified to 7.5" 7.5 " with an inner 5"X5" square drawn on the specimen. Measurements for width and length dimensions were taken before and after laundering. The mean differences and percent shrinkage were calculated.

Seam strength is the maximum force that a seam can withhold before breaking [30]. Seam efficiency is "the ratio expressed in percentage of the breaking force required to rupture the seam to that required to the fabric [31]." In this study, constructed garments were used, so the seams were not selected. Denim A had a superimposed seam, with a stitch density of $8.4 \mathrm{SPI}$, and a flat felt seam, with 11.6 SPI. Denim B had superimposed seam, with a stitch density of 8.8 SPI, and an SS open seam, with 9.6 SPI. Specimens were modified due to using finished garments. For seam strength, ten specimens were cut from both jeans; five from the inner leg seam and 5 from the outer. This allowed for the seams to be parallel to the warp yarns, so the seams were tested in the weft direction. Specimens were cut into 6" 4 " sizes since the seams were already sewn. For fabric strength, ten specimens were cut to 6" $\mathrm{x} 4$ " pieces, five in the warp direction and five in the weft direction. A specimen was placed between the clamps of the tensile testing machine and ran until the seam broke. Seam efficiency was then calculated by taking seam strength divided by fabric strength (weft direction) multiplied by 100 .

Pilling resistance measures the resistance of pill formation and other changes on a fabric's surface using a random tumble pilling apparatus. Pills are balls formed on a fabric through friction or abrasion [32]. Five specimens, 4.13"x4.13" bias cut squares, with the edges sealed with adhesive to prevent fraying, were tested. Specimens and .2" of gray cotton were placed into the test chamber and ran for thirty minutes. Specimens were then compared to the ASTM rating scale and were rated from 1-5, where a lower rating signifies a higher rate of pilling [33].
Colorfastness to crocking determines the color transfer from colored material to white material through rubbing in dry and wet conditions [34]. Colorfastness is the resistance of material to change any of its color as a result of processing. Crocking is the transfer of colorant from the colored surface to a white surface via rubbing [35]. Five 5"x2" specimens were cut on the bias for both the dry and wet test. For dry testing, a white 2 " square test cloth was placed on the finger of the instrument and the test specimen was then secured on the crock meter. The meter was run ten complete times and the test cloth was then compared against the gray scale for staining. The wet test follows the same process, except the white test square was dampened and then blotted prior to being placed on the instrument. Acceptable rating is a 4 or higher.

The data were analyzed using descriptive and inferential statistics. Confidence level used to accept or reject the developed hypotheses was.05. The outcome is detailed in the results and discussion.

\section{Results and Discussion}

Structural and performance attributes of both fast-fashion and classic jeans were tested using t-test analysis. Findings for the structural attributes revealed that Denim A had significantly higher fabric count, yarn size in warp direction, and stitches per inch for the superimposed seams (Table 3). However, the two fabrics did not differ for fabric weight, as well as fabric count and yarn size in the weft direction. The results reflected that structurally, they showed both similarities and differences. Both fabrics had similar classifications. Fabric count was medium, Yarn-size was heavy, and fabric weight was very heavy. However, statistically, they differed significantly from each other. Fabric A had higher count for warp yarns than fabric B. Fabric B was higher in weft and lower in the warp direction. Reverse was true for the yarn size.

Both jeans showed a $3 \mathrm{X} 1$ twill weave pattern (Figure 1). Analyzing the fabric count $(\mathrm{t}=2.829, \mathrm{p}<.05)$ revealed that Denim A had a significantly higher (116.8) count than Denim B which was 107.
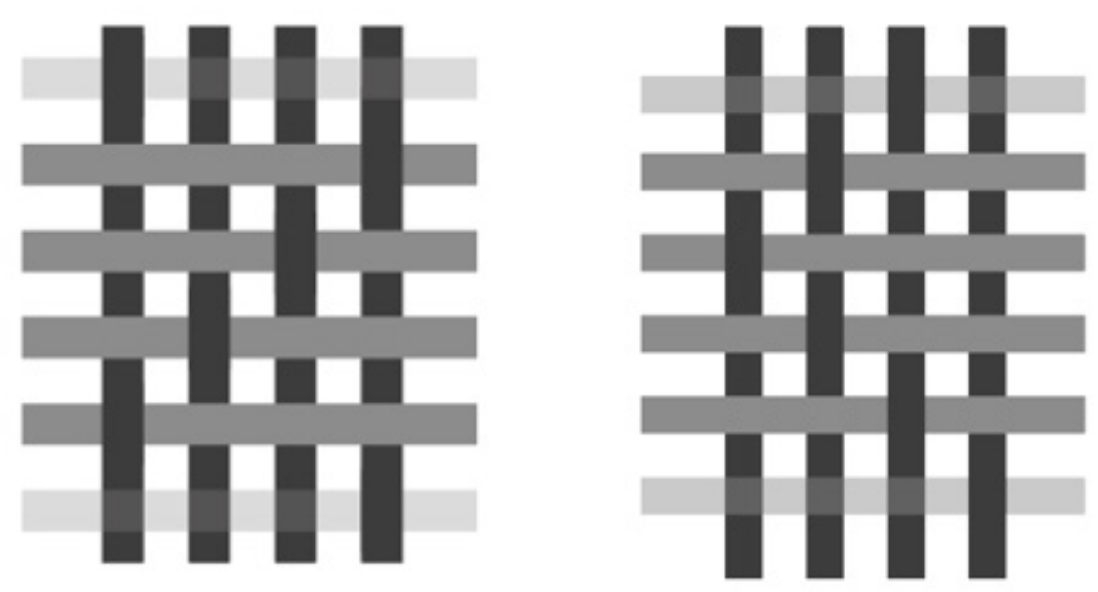

Figure 1: 3x1 twill weave pattern of Denims A and B by Katelyn Haas. 
The performance attributes are presented in hypothesis testing format for nine hypotheses. The results are presented in Table 2.

\section{Hypothesis 1: The breaking strength between two different priced denim jeans will differ}

Breaking strengths of Denims A and B differed significantly, and the proposed hypothesis was accepted. Breaking strength was significantly lower in Denim A than B for both warp $\left(t_{8}=-4.08\right.$, $\mathrm{p}<.05)$ and weft directions $\left(\mathrm{t}_{8}=-4.98, \mathrm{p}<.05\right)$. See Table 4 for details. Contention that fabrics with higher count are stronger than those with lower count.

Table 1: Performance/structural attributes tested with corresponding ASTM or AATCC standard.

\begin{tabular}{|c|c|c|c|}
\hline Attribute & Standard & \# of Specimens & Specimen Size \\
\hline Yarn size & ASTM D2260-03 (approved 2013) & 10 & 1 yd warp/weft \\
\hline Fabric count & ASTM D3775-12 & 5 & $1 " x 1 "$ \\
\hline Fabric weight & ASTM D3776-2013 & 5 & $5 " x 5^{\prime \prime}$ \\
\hline Dimensional Stability & AATCC $96-2012$ (related to ISO 5077) & 5 & *5"x5" \\
\hline Seam Strength \& Efficiency & ASTM D1683-11A & 5 & **6"x4" warp/weft \\
\hline Pilling Resistance & ASTM D3512-2010 & 5 & $4.13 " x 4.13 "$ \\
\hline Colorfastness to Crocking & AATCC $20-2013$ (partly equivalent to ISO $105 \times 12$ ) & 5 & $5 " x 2 "$ \\
\hline Elongation & ASTM D-5034 & 5 & 6"x4" warp/weft \\
\hline Fabric Strength & ASTM D-5034 & 5 & 6"x4" warp/weft \\
\hline Stitches per Inch & & 5 & 1" length \\
\hline Laundering & AATCC 1-2018 & 5 & $5 " \times 5 "$ \\
\hline Conditioning & ASTM D1776 & $\mathrm{N} / \mathrm{A}$ & $\mathrm{N} / \mathrm{A}$ \\
\hline
\end{tabular}

*Specimen sizes were adjusted from 15 "x 15 " to 5 "x 5 " to accommodate working with ready to wear garments used in the study rather than fabric **Specimen sizes were adjusted from 7" 4 " to 6"x4" to accommodate working with already sewn seams

${ }^{* * *}$ Abbreviations: ASTM: American Society for Testing and Materials; AATCC: American Association of Textile Chemists and Colorists

Hypothesis 2: The elongation between two different priced denim jeans will differ

Elongation between the two denims did not differ significantly
(Table 3) and the proposed hypothesis was rejected. This result is different from previous research which stated that breaking strength and elongation are inversely proportionate to each other [36].

Table 2: Hypothesis outcomes.

\begin{tabular}{|c|c|}
\hline Hypothesis & Outcome \\
\hline Breaking strength will differ & Accepted \\
\hline Elongation will differ & Rejected \\
\hline Stitch density will differ & Accepted \\
\hline Colorfastness to crocking will differ & Rejected \\
\hline Staining & Accepted \\
\hline Color Change & Rejected \\
\hline Dimensional stability will differ & Accepted \\
\hline Pilling resistance will differ & Rejected \\
\hline Seam efficiency will differ & Accepted \\
\hline Fabric count will impact seam strength & Accepted \\
\hline Fabric weight will impact seam strength & \\
\hline
\end{tabular}

Table 3: Means, standard deviation, and t-values of fabric count, yarn size, stitches per inch and fabric weight.

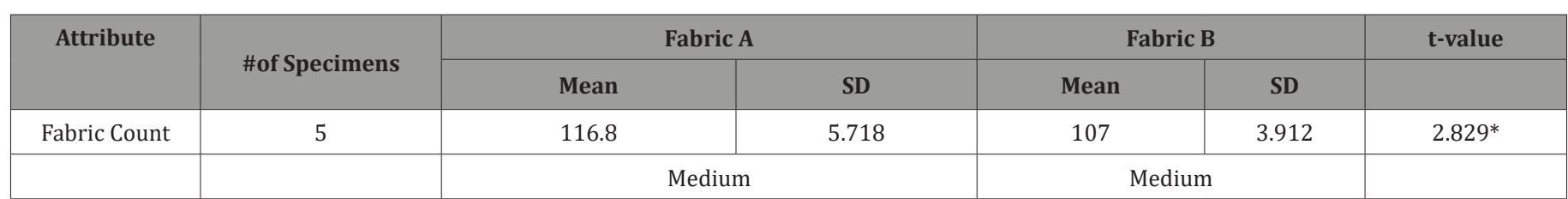




\begin{tabular}{|c|c|c|c|c|c|c|}
\hline \multicolumn{7}{|c|}{ Classification } \\
\hline Warp & & 72.6 & 3.05 & 60 & 2.95 & $5.938^{*}$ \\
\hline Weft & & 44.2 & 2.864 & 46 & 2.302 & $1.107 \mathrm{~ns}$ \\
\hline Yarn Size & 10 & & & & & \\
\hline Classification & & \multicolumn{2}{|c|}{ Heavy } & \multicolumn{2}{|c|}{ Heavy } & \\
\hline Warp & & 73.5 Tex & 4.927 & 104.5 Tex & 4.905 & $13.379 *$ \\
\hline Weft & & 99.8 Tex & 3.58 & 86.2 Tex & 4.04 & $10.675^{*}$ \\
\hline $\begin{array}{l}\text { Stitches per } \\
\text { Inch }\end{array}$ & 5 & & & & & \\
\hline Superimposed & & .548 & 0.548 & 8.8 & 0.447 & $3.16^{*}$ \\
\hline Flat Fell & & 11.6 & 0.894 & 9.6 & 0.894 & \\
\hline SS Unopen & & - & & & & \\
\hline Fabric Weight & 5 & $431.956 \mathrm{~g} / \mathrm{m}^{2}$ & 22.082 & 466.052 & 47.887 & $1.331 \mathrm{~ns}$ \\
\hline Classification & & Very heavy & & Very heavy & & \\
\hline
\end{tabular}

*Significant at $p<.05$ ns not significant

\section{Hypothesis 3: The stitch density between two different priced denim jeans will differ}

Based on the t-test analysis, stitch density of Denim A was significantly higher than denim $B\left(t_{8}=3.16, p<.05\right)$. See Table 3 for individual means. This finding may be explained based on Shweta and Poulomi's study which reported that yarn size impacts performance attributes [37].

\section{Hypothesis 4: The colorfastness to crocking between two different priced denim jeans will differ}

The proposed hypothesis was rejected for dry staining and color change as there was no difference between the two denims. The proposed hypothesis was rejected for wet staining $\left(\mathrm{t}_{8}=1.582, \mathrm{p}<.05\right)$, but was accepted for wet color change $\left(\mathrm{t}_{8}\right.$ $=2.871, \mathrm{p}<.05)$.These results align with Farashahi's research where cheaper denim showed less staining and color change [38]. While the two denims used in this research had the same fiber content, the wash of denims differed. This study's results for colorfastness to crocking was consistent with Farashahi's research [39]. The dry tests showed no staining or color change in either denims.

\section{Hypothesis 5: The dimensional stability between two dif-} ferent priced denim jeans will differ

Dimensional stability within the two denims did not significantly differ for warp $\left(\mathrm{t}_{8}=.0274, \mathrm{p}<.05\right)$ or weft $\left(\mathrm{t}_{8}=-.0262\right.$, $\mathrm{p}<.05$ ), therefore rejecting the proposed hypothesis. See Table 4 for further details. While the difference was not significant, Denim A showed a higher shrinkage in the warp direction than Denim B, which is consistent with Farashahi's research stating that the cheaper jeans showed more shrinkage in length [40]. This information would be interesting to consumers, as jean length is a concern for many shoppers [41].

Table 4: Means, standard deviation, and t-values of dimensional stability, elongation, fabric strength, seam strength, seam efficiency, pilling resistance, and color fastness to crocking.

\begin{tabular}{|c|c|c|c|c|c|c|}
\hline \multirow[t]{2}{*}{ Attribute } & \multirow[t]{2}{*}{ \# of Specimens } & \multicolumn{2}{|c|}{ Fabric A } & \multicolumn{2}{|c|}{ Fabric B } & \multirow[t]{2}{*}{ t-value } \\
\hline & & Mean & SD & Mean & SD & \\
\hline Dimensional Stability & \multicolumn{6}{|c|}{5} \\
\hline Warp & & $1.53 \%$ & 0.084 & $1.39 \%$ & 0.062 & 0.0274 \\
\hline Weft & & $1.17 \%$ & 0.069 & $1.28 \%$ & 0.052 & -0.0262 \\
\hline Elongation & \multicolumn{6}{|c|}{5} \\
\hline Warp & & 0.458 & 0.026 & 0.744 & 0.15 & $-3.75^{*}$ \\
\hline Weft & & 0.254 & 0.023 & 0.366 & 0.054 & $-3.81 *$ \\
\hline Fabric Strength & \multicolumn{6}{|c|}{5} \\
\hline Warp & & $\begin{array}{l}118.051 \\
\mathrm{lbs} / \mathrm{in}^{2}\end{array}$ & 9.781 & $\begin{array}{l}218.79 \\
\mathrm{lbs} / \mathrm{in}^{2}\end{array}$ & 48.393 & $-4.08^{*}$ \\
\hline Weft & & $\begin{array}{c}91.84 \\
\mathrm{lbs} / \mathrm{in}^{2}\end{array}$ & 10.428 & $\begin{array}{c}145.272 \\
\mathrm{lbs} / \mathrm{in}^{2}\end{array}$ & 18.77 & $-4.98^{*}$ \\
\hline
\end{tabular}




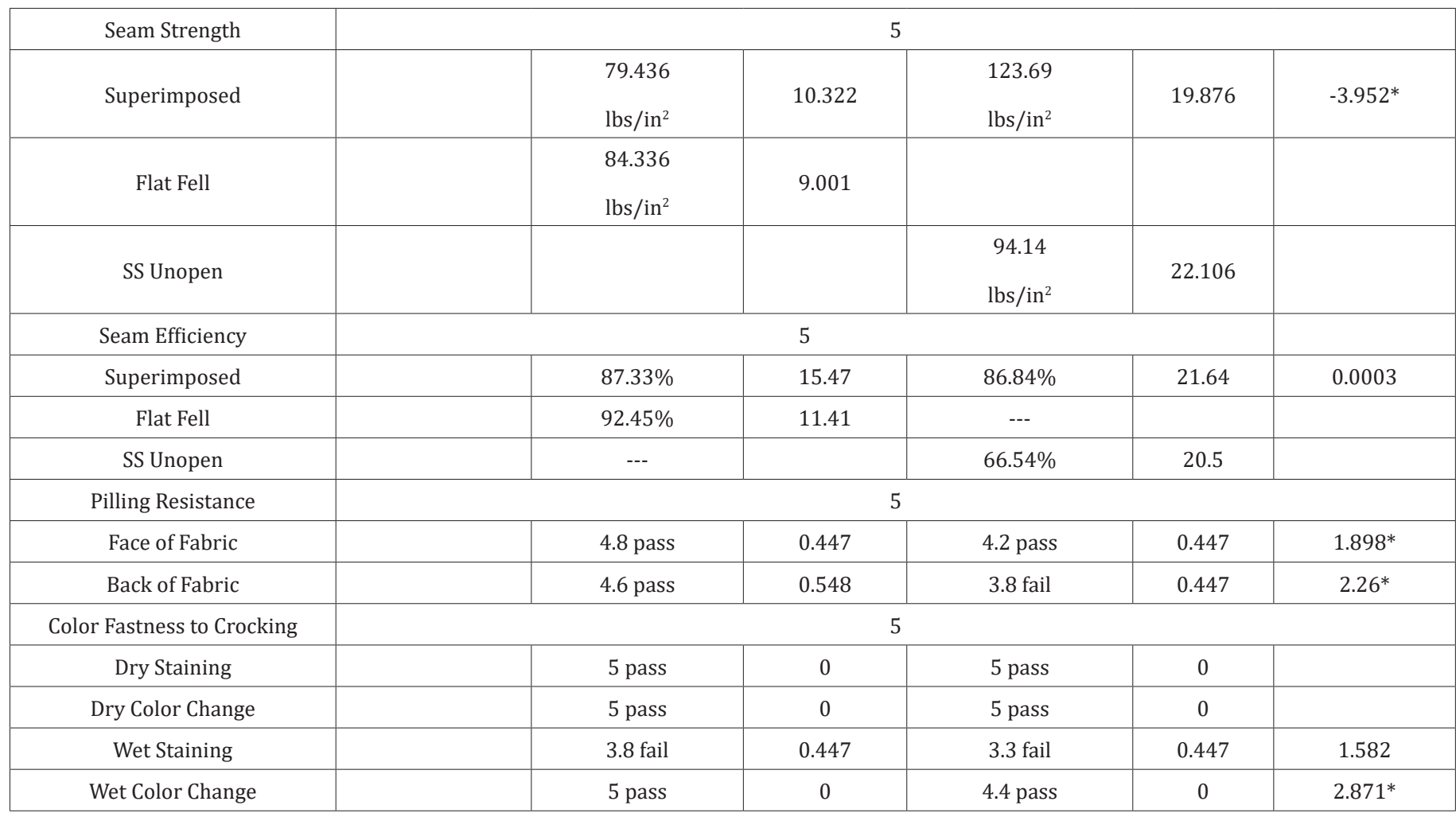

*Significant at $p<.05$ ns not significant

\section{Hypothesis 6: The pilling resistance between two different priced denim jeans will differ}

The proposed hypothesis was accepted as Denim A showed significantly higher passing rates on the face of the fabric $\left(t_{8}\right.$ $=1.898, p<.05)$ and the back of the fabric $\left(t_{8}=2.26, p<.05\right)$. See Table 4 for details. While conducting this test, the cork lining the tumbler of the machine burst creating a lot of debris tumbling with the specimens of Denim B. The lower ratings could be due to that or any treatments the jeans went through for dying and destressing, as the fabric appeared softer than Denim A to begin with.

\section{Hypothesis 7: The seam efficiency between two different priced denim jeans will differ}

Seam efficiency between the two denims did not differ $\left(t_{8}\right.$ $=.0003,<.05$ ) and the proposed hypothesis was rejected. Only the outer leg seams were compared as they were the same.

\section{Hypothesis 8: The fabric count will impact seam strength}

Denim A warp thread count was significantly higher $\left(t_{8}=5.938\right.$, $\mathrm{p}<.05)$, while it's weft count was lower $\left(\mathrm{t}_{8}=1.107\right.$, $\left.\mathrm{p}<.05\right)$. Denim A averaged a slightly higher fabric count at 116.8 compared to Denim B's 107. The overall count of Denim A was significantly higher $\left(\mathrm{t}_{8}=2.829, \mathrm{p}<.05\right)$. Denim $\mathrm{B}$ showed significantly higher seam strength $\left(t_{8}=-3.952, p<.05\right)$. The proposed hypothesis was accepted.

\section{Hypothesis 9: Fabric weight will impact seam strength}

While both denims classified as very heavy for fabric weight,
Denim B weighed slightly more, but did not differed significantly $\left(t_{8}=1.331, p<.05\right)$. The proposed hypothesis was accepted.

\section{Conclusion}

While the yarn size and fabric weight of both denims did not differ, Fabric A showed a higher fabric count. However, Fabric B performed better in fabric strength and seam strength. Overall, many hypotheses were accepted and differences between the denims were seen. While differences with structural and performance attributes were found, they seemed to have no impact on seam efficiency as there was little difference between the tested denims. Exploring similar variables amongst denims of different fiber content, use of different seams, and variations in SPI and tex would all be interesting to further investigate. While this research may be found helpful by manufacturers in the industry, it is aimed towards the consumer. Quality of fast fashion garments are often talked about but can be misunderstood.

\section{Limitations}

The use of finished garments caused various limitations throughout this study. Specimen sizing needed to be adjusted to work with the quantity of finished seams and fabric offered from a final garment. This possibly had the largest impact on dimensional stability as the specimens were reduced by $50 \%$. The finished seams were sewn parallel to the warp yarns, so seam strength and efficiency were only able to be tested in the weft direction. With the differing seams used on the inner legs of the two denims, only the outer leg seams, using a superimposed seam, were able to be compared. With finished seams being tested, little exploration was 
done on quality potentially offered by differing seams. This study also only examined one garment from a single fast fashion retailer. To gage on retailer quality overall, more research is necessary on a variety of garments with different structural properties.

\section{Future Research}

Similar studies could be conducted further expanding concepts on the quality of garments in relation to price. Conducting future research on different denims from various fast fashion brands could be valuable information to consumers looking to save money. Examining the quality of different priced denims from the same brand could be beneficial. This study focused on the sewn seams of finished garments. Adjusted seams could even be sewn from the fast fashion fabric used to test if the chosen SPI, thread count, and stitch/seam in the finished garment was the best option. This study focused on $100 \%$ cotton denims, but examining different fiber contents, for example, blends with spandex, would be interesting as denim with stretch is popular amongst consumers and within fast fashion. With knowing that most fast fashion companies give their clothing a bench marker of 10 launderings before quality begins to diminish, conducting a study on fast fashion garments with laundering as the independent variable would offer more insight to consumers on the quality of their purchases in hand with the care they provide.

This study was started as exploratory research on a basic, classic garment found in most individuals' closets. The purpose of it was to not only provide manufacturers with data regarding quality, but to inspire consumers to further understand the quality they are paying for. A common discussion is the purchasing of basic t-shirts and whether it's more beneficial to the consumer to purchase cheaper shirts more frequently or invest in a couple of shirts intended to last longer. This research could be conducted on garments from different brands at various price points, similarly priced garments from various brands, or even various garments from the same retailer. Examining the quality of differently priced garments from the same retailer could help empower consumers to think more consciously about their purchases.

\section{Acknowledgement}

A thank you to Dr. Chowdhary as the faculty advisor on this research. Thank you for your patience and support during the past year, as well as your invaluable expertise in formulating the hypotheses and interpreting the results. I appreciate your encouragement of heart and willingness to challenge my comfort zone.

\section{Conflict of Interest}

Authors declare no conflict of interest.

\section{References}

1. Hancock GA (2016) Vintage Done Right: Tracing the Secondhand Clothing Supply Chain. Occidental College, USA.
2. Joy A, Sherry J, Venkatesh A, Wang J, Chan R (2012) Fast Fashion, Sustainability, and the Ethical Appeal of Luxury Brands. Fashion Theory 16(3): 273-295.

3. Joy et al. 280 .

4. Malek S, Jaouchi B, Khedher F, Ben Said S, Cheikhrouhou M (2017) Influence of some sewing parameters upon the sewing efficiency of denim fabrics. The Journal of The Textile Institute 108(12): 2073-2085.

5. Jim Z (2013) In Trendy World of Fast Fashion, Style's Aren't Made to Last. NPR.

6. Bick R, Halsey E, Ekenga CC (2018) The global environmental injustice of fast Fashion. Environmental Health 17(92): 1.

7. Joy A, et al. Fast Fashion, Sustainability. Ethical Appeal: 283.

8. Annie L (2016) An Analysis of the Fast Fashion Industry." Senior Projects Fall 30: 17.

9. Joy A, et al. Fast Fashion, Sustainability. Ethical Appeal: 283.

10. Joy A, et al. Fast Fashion, Sustainability, Ethical Appeal: 275.

11. Chowdhary U (2019) Impact of Interfacings and Lining on Breaking Strength, Elongation and Duration of the Test for Knitted Wool." International Journal of Textile Science and Engineering 3(125): 1.

12. Chowdhary U, Impact of Interfacing and Lining: 6.

13. Chowdhary U, Poynor D (2006) Impact of stitch density on seam strength, seam elongation, and seam efficiency. International Journal of Consumer Studies 30(6): 561-568.

14. Chowdhary U, Poynor D, Impact of stitch density: 567.

15. Chowdhary U, Wentela C (2018) Impact of Support Fabrics on Breaking Strength, Elongation, and Time Taken for the Test for Woven Fabrics in Different Fiber Contents. International Journal of Polymer and Textile Engineering 5(3): 1-6.

16. Chowdhary U, Wentela C, Impact of Support Fabrics: 5.

17. Shweta T, Poulomi S (2018) A Study on the Effect of Sewing Thread Count and Stitch Density on the Seam Performance of Denim Fabric." Research Review International Journal of Multidisciplinary 3(11): 34.

18. Poulomi S, A Study on the Effect of Sewing Thread Count: 34.

19. Malek S, et al. Influence of some Sewing Patterns: 2073.

20. Malek S, et al. Influence of some Sewing Patterns: 2084.

21. Farashahi BG (2016) Quality Evaluation of Jeans at Three Different Price Categories." Theses and Dissertations- Retailing and Tourism Management 10: 2 .

22. Farashahi, Quality Evaluation of Jeans: 78.

23. Farashahi, Quality Evaluation of Jeans: 89.

24. Card A, Moore MA, Ankeny M (2006) Garment washed jeans: impact of launderings on physical properties." International Journal of Clothing Science and Technology 18(1): 43-52.

25. Moore C, Ankeny, Garment Washed Jeans: 47 .

26. Chowdhary U, Wroblewski SA (2016) Textile Analysis Laboratory Manual: 11 
27. Chowdhary U, Wroblewski SA, Textile Analysis Laboratory Manual: 19. 28. Chowdhary U, Wroblewski SA, Textile Analysis Laboratory Manual: 37.

29. Chowdhary U, Wroblewski SA, Textile Analysis Laboratory Manual: 45

30. Chowdhary U, Wroblewski SA, Textile Analysis Laboratory Manual: 75.

31. Chowdhary U, Wroblewski SA, Textile Analysis Laboratory Manual: 75.

32. Chowdhary U, Wroblewski SA, Textile Analysis Laboratory Manual: 87.

33. Chowdhary U, Wroblewski SA, Textile Analysis Laboratory Manual: 88.

34. Chowdhary U, Wroblewski SA, Textile Analysis Laboratory Manual: 99.

35. Chowdhary U, Wroblewski SA, Textile Analysis Laboratory Manual: 99.
36. Merkel RS (1991) Textile Product Serviceability. Macmillan, New York, USA.

37. Shweta T, Poulomi S, Effect of Sewing Thread Count and Stitch Density. 34.

38. Farashahi, Quality Evaluation of Jeans. 78.

39. Farashahi, Quality Evaluation of Jeans. 78.

40. Farashahi, Quality Evaluation of Jeans. 89.

41. Rahman 0 (2011) Understanding Consumers' Perceptions and Behaviors: Implications for Denim Jeans Design. Journal of Textile and Apparel, Technology and Management 7(1): 10. 